\title{
Agrobiodiversity Index scores show agrobiodiversity is underutilized in national food
} \section{systems}

\author{
Sarah K. Jones ${ }^{1 凶}$, Natalia Estrada-Carmona ${ }^{\circledR 1}$, Stella D. Juventia ${ }^{10}{ }^{1,2}$, M. Ehsan Dulloo ${ }^{3}$, \\ Marie-Angelique Laporte ${ }^{1}$, Chiara Villani ${ }^{4}$ and Roseline Remans $\mathbb{D}^{5}$
}

The diversity of plants, animals and microorganisms that directly or indirectly support food and agriculture is critical to achieving healthy diets and agroecosystems. Here we present the Agrobiodiversity Index (based on 22 indicators), which provides a monitoring framework and informs food systems policy. Agrobiodiversity Index calculations for 80 countries reveal a moderate mean agrobiodiversity status score (56.0 out of 100), a moderate mean agrobiodiversity action score (47.8 out of 100$)$ and a low mean agrobiodiversity commitment score (21.4 out of 100), indicating that much stronger commitments and concrete actions are needed to enhance agrobiodiversity across the food system. Mean agrobiodiversity status scores in consumption and conservation are 14-82\% higher in developed countries than in developing countries, while scores in production are consistently low across least developed, developing and developed countries. We also found an absence of globally consistent data for several important components of agrobiodiversity, including varietal, functional and underutilized species diversity.

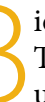
iodiversity is at risk of rapid global declines and extinctions ${ }^{1}$. These risks extend to agrobiodiversity, the domesticated and undomesticated plants, animals and microorganisms that contribute to food and agriculture, including those that provide pollination, nutrient cycling, pest control and other ecological functions supporting production systems ${ }^{2}$. Global conservation assessments from the International Union for Conservation of Nature Red List are available for $30 \%$ of known edible plant species, and $11 \%$ of these are classified as threatened, putting them at risk of extinction ${ }^{3}$. Although the use of traditional crop varieties persists ${ }^{4}$, of more than 6,000 different plant species cultivated for food, just 9 (sugarcane, maize, rice, wheat, potatoes, soybeans, oil-palm fruit, sugar beet and cassava) contribute around $66 \%$ of total crop production ${ }^{5}$. Currently, $26 \%$ of the world's 7,745 remaining local livestock breeds are believed to be at risk of extinction, and an estimated $33 \%$ of fish stocks are overfished ${ }^{5}$. The likelihood of a bee, one of world's primary crop pollinators, being found in any given place in Europe and North America has declined by a third since the $1970 \mathrm{~s}^{6}$.

The overdependence on a handful of species, varieties and breeds and the disappearance of pollinators and other organisms that support food and agriculture threaten the sustainability of our food system and affect human and environmental health ${ }^{7}$. Diets low in diversity are often inadequate in micronutrients, increasing the risk of malnutrition ${ }^{8,9}$. Monocultures and other simplified production systems are more prone to pest and disease outbreaks ${ }^{10}$, lower soil quality ${ }^{11,12}$ and unstable yields ${ }^{12-14}$ and are at risk for more frequent harvest losses ${ }^{15}$. Crises such as the Irish famine triggered by potato blight in 1845 or the outbreak of the Panama banana disease in 1950s show that overreliance on a single crop species (and one or a few varieties thereof) can pose serious risks to food security and economic stability, undermining the resilience of the food system.

The Food and Agriculture Organization's (FAO's) State of the World's Biodiversity for Food and Agriculture 2019 report represents a major milestone in highlighting agrobiodiversity's importance and decline, as well as the need for better agrobiodiversity monitoring to make the transition towards more sustainable and resilient food systems ${ }^{5}$. Most global analyses of the state of agrobiodiversity to date focus on single components of agrobiodiversity (such as neglected species ${ }^{3}$, crop diversity ${ }^{16,17}$ or fish richness ${ }^{18}$ ) and do not integrate information on agrobiodiversity across the food system. Yet agrobiodiversity exists on our plates, in production systems and in conservation, in each place contributing to different food system sustainability outcomes and influenced by different management actions and policy decisions.

Here we present the Agrobiodiversity Index (ABDI), a food systems approach to collating agrobiodiversity data aimed at enabling policymakers, non-governmental organizations, civil society leaders and businesses to understand relationships between dimensions of agrobiodiversity across the food system, compare agrobiodiversity use and conservation across countries, and identify priority interventions to enhance agrobiodiversity for more sustainable food systems (Fig. 1). The ABDI uses 22 indicators, each with one or more associated sub-indicators to assess the status of, and actions or commitments to enhance, agrobiodiversity's contribution to sustainability outcomes across three pillars of the food system: consumption and markets, contributing to healthy diets ${ }^{8,19,20}$ (pillar 1); production systems, contributing to agricultural sustainability ${ }^{12,21-26}$ (pillar 2); and genetic resource conservation, contributing to safeguarding future use option $\mathrm{s}^{27-29}$ (pillar 3) (see Table 1 for the details). The indicators are aggregated to provide composite status, action and commitment scores in consumption, production and conservation. We apply the ABDI to countries around the world, using globally available public datasets. All scores generated from the ABDI are on a scale of 0 to 100 , with 0 representing the lowest (least desirable) and 100 the highest (most desirable) score. High scores can be interpreted as showing where agrobiodiversity status, actions or 


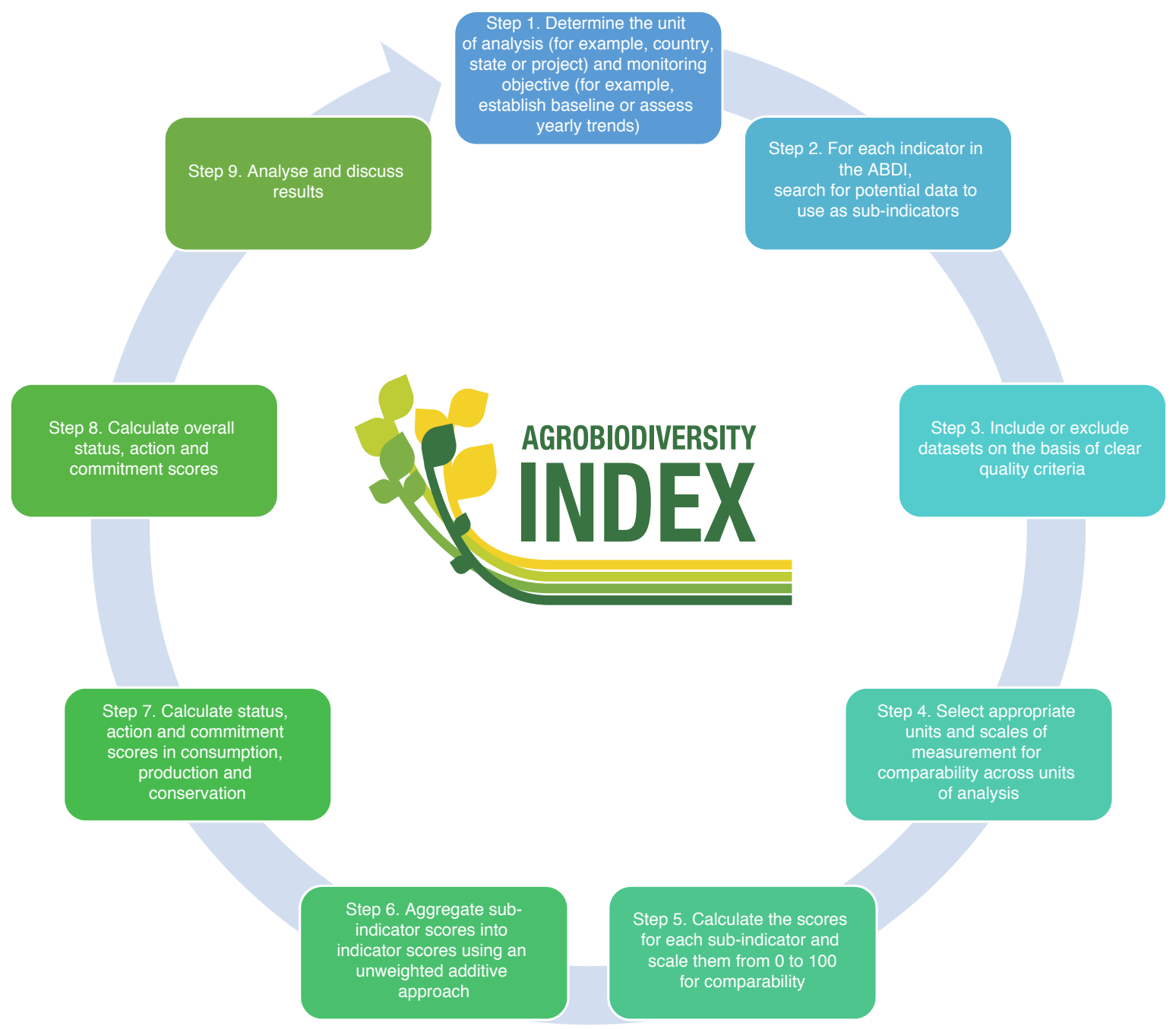

Fig. 1 | ABDI approach to compiling data on agrobiodiversity. Applying the ABDI involves selecting the unit and scope of analysis (step 1), identifying appropriate datasets for the 22 indicators (steps 2 and 3), calculating and scaling the sub-indicator scores (steps 4 and 5), and aggregating these scores into composite measures (steps 6-8) to explore the use and conservation of agrobiodiversity across the food system (step 9). The ABDI logo was designed by Bioversity International (reproduced with permission).

commitments are high relative to a global threshold, which represents the ideal case for ensuring agrobiodiversity use and conservation to enhance food system sustainability. Conversely, a low score shows where agrobiodiversity is relatively poorly used and conserved, hindering sustainability. Further information on how the datasets were selected, analysed, scaled and aggregated is provided in the Methods and Supplementary Information.

\section{Results}

Global scores. We found consistent data for 17 of the 22 ABDI indicators across 80 countries (Fig. 2), consolidating information from 43 sub-indicators (Table 2). On the basis of the mean scores across these countries, the ABDI shows that there is a moderate level of agrobiodiversity in the global food system (status score $=56.0$, s.d. $=7.7$ ), coupled with a moderate level of action taken (action score $=47.8$, s.d. $=17.3$ ) and a low level of political commitment to enhance agrobiodiversity use and conservation (commitment score $=21.4$, s.d. $=9.8$ ). Status scores are the highest in consumption $(\mu=69.9$, s.d. $=13.2)$, followed by production $(\mu=49.4$, s.d. $=8.6)$ and conservation $(\mu=48.6$, s.d. $=14.6)$. Action scores are the highest in production $(\mu=57.1$, s.d. $=11.6)$, followed by consumption $(\mu=56.2$, s.d. $=41.6)$ and finally conservation $(\mu=30.2$, s.d. $=30.7)$. Commitments follow almost the reverse pattern, with the strongest commitments made to improving levels of agrobiodiversity in conservation $(\mu=36.2$, s.d. $=15.3)$, followed by production $(\mu=23.5$, s.d. $=14.4)$, and the weakest to enhancing agrobiodiversity in consumption $(\mu=4.4$, s.d. $=8.4)$. This indicates that political commitments to agrobiodiversity are not consistently translating into concrete actions, and stronger commitments should be made to enhance the use and conservation of agrobiodiversityparticularly in farms and on our plates.

Indicator scores reveal which dimensions of agrobiodiversity are strongly or weakly represented in our global food system (Table 2). Status indicator scores in consumption are the highest for underutilized species use $(\mu=84.4$, s.d. $=18.615 .1)$, indicating that people in most countries in our analysis rely on foods other than cereals, roots and tubers for at least $60 \%$ of their dietary energy intake (cereals, roots and tubers are overconsumed globally ${ }^{7}$, making other foods relatively underutilized). Species diversity in consumption is moderate at the global level $(\mu=57.4$, s.d. $=17.4)$, as measured 
Table 1 | ABDI indicator framework

\begin{tabular}{|c|c|c|c|}
\hline $\begin{array}{l}\text { Measurement } \\
\text { category }\end{array}$ & Pillar & Indicator & Aims to capture \\
\hline \multirow[t]{2}{*}{ Status } & Consumption & Varietal diversity & $\begin{array}{l}\text { Food consumption diversity at the varietal level (for example, basmati, long grain or wild rice) or breed level } \\
\text { (for example, Saddleback, Duroc or Hereford pig), since each variety or breed has a unique nutritional value. For } \\
\text { example, carotenoid levels are almost null in the Cavendish banana cultivar, whereas specific local cultivars from } \\
\text { Papua Guinea contain }>100 \mathrm{mg} \text { of carotenoids }{ }^{65} \text {. }\end{array}$ \\
\hline & & Species diversity & $\begin{array}{l}\text { Food consumption diversity at the species level (for example, apple, orange or pear), since each species has } \\
\text { unique nutritional characteristics. The larger the dietary species richness, the larger the likelihood of nutrient } \\
\text { adequacy }{ }^{65} \text {. For example, maize is high in carbohydrates, beans are rich in protein and fibre, and pumpkin is rich } \\
\text { in vitamin } A^{65} \text {. }\end{array}$ \\
\hline
\end{tabular}

Functional diversity Food consumption diversity at the nutritional function level-that is, the diversity of food groups (for example, cereals, vegetables or fruits) or nutrients required for a healthy diet, since each food group has a unique nutritional value. For example, a healthy diet for women requires the daily consumption of at least five functional food groups ${ }^{66}$

Underutilized Use of underutilized or neglected species, varieties or breeds in food consumption, which are often rich in species Use of underutilized or neglected species, varieties or breeds in food consumption, which are often rich in
nutrients that play a critical and often undervalued role in people's diets ${ }^{65}$. Many underutilized plant species have excellent nutritional profiles? ${ }^{7}$. For example, indigenous vegetables such as roselle and hair lettuce are known to be important sources of iron, while others such as moringa (Moringa oleifera), African nightshade (Solanum scabrum) and jute mallow (Corchorus olitorius) are excellent sources of provitamin $A^{67}$.

Production Varietal diversity

Agricultural production diversity at the varietal or breed level, since each variety or breed has a unique agronomic and ecological value that can be managed to improve sustainability outcomes. For example, cropping varietal mixtures can support insect pest control and improve yields and economic and nutritional outcomes $^{68}$.

Species diversity Agricultural production diversity at the species level, since increased crop, livestock, tree or fish species diversity is often associated with improved ecosystem functioning $12,33,69,70$. For example, complex rice systems integrating fish, duck and azolla in rice cropping have been shown to increase system resilience compared with conventional or organic monocultures ${ }^{71}$.

Functional diversity Agricultural production diversity at the level of agronomic or ecological traits (for example, drought tolerance, disease resistance, root depth or leaf area), since increased functional trait diversity is associated with improved ecosystem functioning (for example, soil nutrient cycling or water purification) that is beneficial for agricultural and natural systems ${ }^{72-74}$. For example, rotating potato with cover crops and deep-rooted crops such as alfalfa or small grains can improve soil quality, disease suppression and tuber yield and quality ${ }^{75}$.

Underutilized species Agricultural production of local, indigenous, traditional or neglected species, varieties or breeds, which are often better adapted to local environmental conditions, making production systems more resilient to environmental stressors $^{76}$. For example, traditional bean varieties in Uganda were found to have higher resistance than modern varieties to pests and diseases ${ }^{77}$.

Pollinators and natural enemies

Diversity of crop pollinators and natural enemies of crop, fish and livestock pests, where these provide pollination and biological pest control services to agriculture. For example, most fruits and vegetables are animal-pollinator-dependent crops $^{24}$, and fruit and vegetable production systems with an abundance of suitable pollinator species are more likely to have plentiful harvests, benefiting agriculture and biodiversity ${ }^{78}$.

Soil biodiversity Diversity of soil organisms, which support nutrient cycling and maintain healthy soils, which are fundamental to sustainable agriculture production ${ }^{25}$.

Landscape

complexity

Complexity of agricultural landscape composition and configuration, since more complex landscapes (for example, with a higher proportion of semi-natural habitat) are associated with higher levels of biodiversity and improved ecosystem service provision to agriculture (for example, pollination and pest control) ${ }^{35}$. For example, Fahrig et al. ${ }^{79}$ show that decreasing crop field size is consistently associated with positive effects on farmland biodiversity, benefiting from easy access to the semi-natural field boundary habitats. The proportion of natural habitat can be increased on-farm through flower strips, hedgerows and set-aside, and off-farm by safeguarding forests, shrubland and grassland remnants.

Conservation Varietal diversity

Diversity of genetic resources for food and agriculture within individual crops and livestock species in conservation, since each variety or breed has unique agronomic, ecological and nutritional traits. Their conservation for future use is critical for identifying desirable traits for breeding varieties and breeds adapted to new conditions ${ }^{80}$. For example, the conservation of many varieties of a single crop will help ensure the future capacity of that crop to adapt to droughts, become resistant to new pests and diseases, or provide better nutritional functions ${ }^{45}$.

Species diversity Diversity of genetic resources for food and agriculture in conservation at the species level, since each species has unique agronomic, ecological and nutritional traits. Their conservation for future use is critical for identifying new desirable traits for breeding crops, livestock and fish adapted to new conditions. For example, different wild relatives of crops, livestock and fish (including their ancestors) can provide novel adaptive and/or resistance genes as a result of evolutionary processes in nature that can be used in breeding.

Functional diversity Diversity of genetic resources for food and agriculture at the species and varietal/breed levels in conservation that provide essential roles and functions at the level of agronomic, ecological and nutritional traits to meet consumer demands and overcome production challenges. For example, genetic sequencing was used to identify traits associated with drought tolerance in chickpeas ${ }^{81}$.

Underutilized Conservation of local, indigenous, traditional, neglected and underutilized species and varieties or breeds used species for food and agriculture, including their wild relatives, landraces and breeds, some of which are threatened with extinction after millennia of selection by farmers ${ }^{82}$. 
Table 1 | ABDI indicator framework (Continued)

\begin{tabular}{|c|c|c|c|}
\hline $\begin{array}{l}\text { Measurement } \\
\text { category }\end{array}$ & Pillar & Indicator & Aims to capture \\
\hline \multirow[t]{4}{*}{ Action } & Consumption & $\begin{array}{l}\text { Management } \\
\text { practices supporting } \\
\text { agrobiodiversity }\end{array}$ & $\begin{array}{l}\text { Tools or mechanisms to foster the consumption of diverse foods for healthy diets (for example, dietary } \\
\text { guidelines). }\end{array}$ \\
\hline & \multirow[t]{2}{*}{ Production } & $\begin{array}{l}\text { Diversity-based } \\
\text { practices }\end{array}$ & $\begin{array}{l}\text { Adoption of diversity-based farming practices, such as intercropping, agroforestry, crop rotation and mixed } \\
\text { farming systems, which help increase the level of diversity and resilience in production systems. }\end{array}$ \\
\hline & & $\begin{array}{l}\text { Management } \\
\text { practices supporting } \\
\text { agrobiodiversity }\end{array}$ & $\begin{array}{l}\text { Adoption of other farming practices that help maintain and enhance levels of agrobiodiversity, such as reduced } \\
\text { agrochemical inputs and reduced tillage. }\end{array}$ \\
\hline & Conservation & $\begin{array}{l}\text { Management } \\
\text { practices supporting } \\
\text { agrobiodiversity }\end{array}$ & $\begin{array}{l}\text { Tools or mechanisms to protect and safeguard genetic resources for food and agriculture for future use, such as } \\
\text { gene banks that conserve accessions of plant genetic resources for food and agriculture. }\end{array}$ \\
\hline \multirow[t]{3}{*}{ Commitment } & Consumption & $\begin{array}{l}\text { Commitments } \\
\text { supporting } \\
\text { agrobiodiversity }\end{array}$ & $\begin{array}{l}\text { Policy commitments to enhancing agrobiodiversity in consumption for healthy diets, disaggregating policies } \\
\text { that mention agrobiodiversity in this context from those that define strategies or set targets to achieve change. } \\
\text { Relevant commitments include, for example, Bhutan's national strategy to promote local varieties and their } \\
\text { market opportunities. }\end{array}$ \\
\hline & Production & $\begin{array}{l}\text { Commitments } \\
\text { supporting } \\
\text { agrobiodiversity }\end{array}$ & $\begin{array}{l}\text { Policy commitments to enhancing agrobiodiversity in production for sustainable agriculture, disaggregating } \\
\text { policies that mention agrobiodiversity in this context from those that define strategies or set targets to achieve } \\
\text { change. Relevant commitments include, for example, Somalia's national target to ensure that, by } 2030 \text {, areas } \\
\text { under agriculture, aquaculture and forestry are managed sustainably through diversifying management } \\
\text { practices, such as with agroforestry. }\end{array}$ \\
\hline & Conservation & $\begin{array}{l}\text { Commitments } \\
\text { supporting } \\
\text { agrobiodiversity }\end{array}$ & $\begin{array}{l}\text { Policy commitments to enhancing agrobiodiversity in conservation for future use options, disaggregating policies } \\
\text { that mention agrobiodiversity in this context from those that define strategies or set targets to achieve change. } \\
\text { Relevant commitments include, for example, India's national target to conserve } 70 \% \text { of the genetic diversity } \\
\text { of crops, including their wild relatives and other socio-economically valuable plant species, while respecting, } \\
\text { preserving and maintaining associated indigenous and local knowledge. }\end{array}$ \\
\hline
\end{tabular}

The 22 indicators in the ABDI are designed to measure agrobiodiversity within each pillar of the food system (consumption, production and conservation) across three measurement categories (status, action and commitment).

by Shannon's diversity index ${ }^{30}$ of food items in supply in kcal per capita per day. These two indicators together show that the average food supply at the national level contains many different food items beyond cereals, roots and tubers, but a few food items dominate. Functional diversity in consumption, as measured by avoided diet-related disability-adjusted life years as a proxy for nutritionally balanced diets, is relatively high globally $(\mu=67.8$, s.d. $=15.5)$ but nonetheless accounted on average for 6,339 disability-adjusted life years per 100,000 adults in 2017 for the countries in our analysis.

In production, status scores are the highest for species diversity $(\mu=60.4$, s.d. $=12)$. This reflects relatively high (although globally variable) percentages of diversified cropland and richness of freshwater fish species, together with moderate and less variable livestock species diversity, crop species diversity and crop species richness. The variation in country scores across sub-indicators reveals that while crop richness tends to be evenly distributed across production areas in many countries, the number of crop species in production at the national level could substantially increase in most countries. At present, $58 \%$ of countries have a score of 60 or lower for crop richness, meaning that the number of crops in production needs to increase by over a third to reach the target of 123 species set by the current global leader (China). This target will not be equally easy for all countries to reach due to their varying land areas, climatic and soil conditions, and access to knowledge, seeds and other inputs, but it should be attainable for all given that it represents a small share of the edible crop species generally available. Across the 80 countries, we find moderate status scores for varietal/breed diversity (representing the diversity of livestock breeds), soil biodiversity and landscape complexity, indicating that there is an opportunity to substantially increase each of these for more sustainable production systems.

In conservation, global status scores for varietal diversity and species diversity are moderate $(\mu=57.9$, s.d. $=23.1$ and $\mu=57.2$, s.d. $=15.1$, respectively). Varietal diversity represents the diversity of native crop varieties conserved in gene banks relative to the global leader (France). The moderate global score indicates that many countries have relatively low levels of native crop varieties conserved ex situ. The scores for native crop diversity stored in gene banks are not adjusted to account for differences in the total number of native crop varieties in a country (for example, based on crop centres of origin ${ }^{31}$ ), because these ecological regions do not match country boundaries, and differences in the number of native crop varieties between regions are not well quantified. Countries with high scores that are in ecologically extreme regions (for example, boreal or arid biomes) are therefore likely to have exceptionally high levels of native crop varietal diversity in gene banks. The species diversity score reflects moderate diversity of native plant species stored in gene banks relative to the global leader (South Africa) and moderate crop wild relative species occurrence diversity. The global scores for underutilized species are low, as measured by the representativeness of wild useful plants in ex situ and in situ conservation $(\mu=30.7$, s.d. $=12.9)$.

Action indicator scores reveal that management practices supporting agrobiodiversity in consumption for healthy diets are at moderate levels $(\mu=56.2$, s.d. $=41.6)$. This reflects a highly variable global availability of national dietary guidelines and food composition tables, with less than half (33) of countries in our analysis having both. Actions relating to agrobiodiversity in production are the highest for diversity-based practices $(\mu=76.7$, s.d. $=22.8)$, as measured by the proportion of agricultural land with both pasture and cropland at $10 \mathrm{~km}^{2}$ scales. While the local availability of livestock supports crop-livestock integration for sustainable agriculture (such as integrated nutrient management), the score is not a measure of where crop-livestock integration is actually practiced (since no such global dataset exists), so this positive result should be interpreted with caution. Scores are low for the action indicator on management practices supporting agrobiodiversity in production $(\mu=37.4$, s.d. $=7.6)$. On the basis of the underlying sub-indicators, 

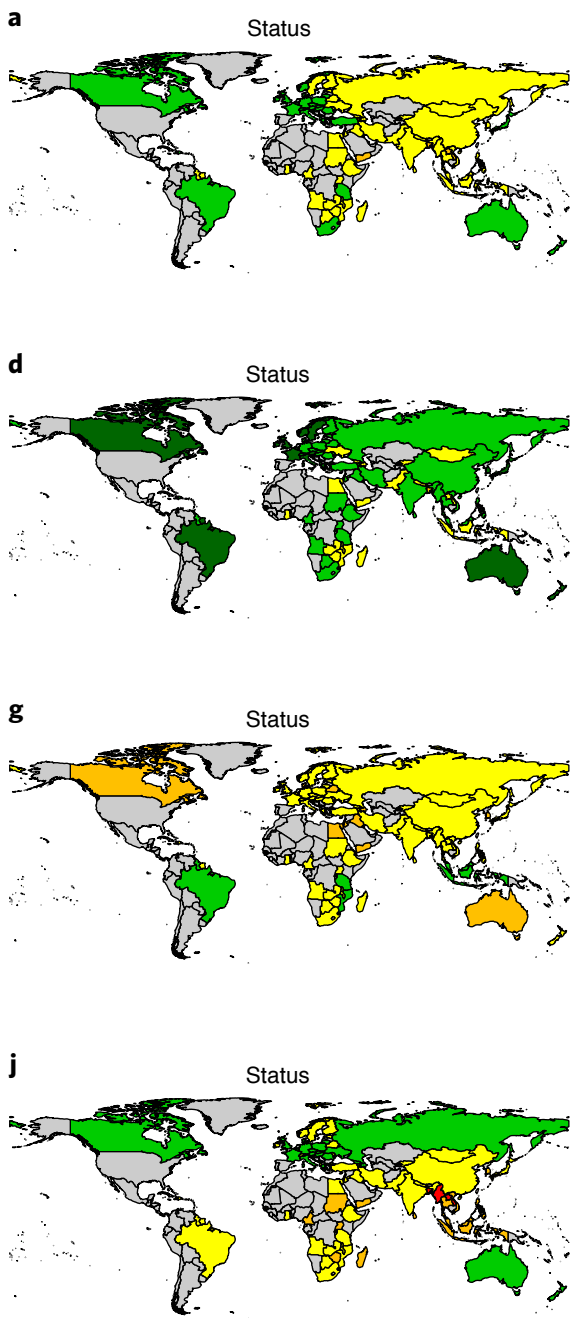

Agrobiodiversity across the whole food system

b

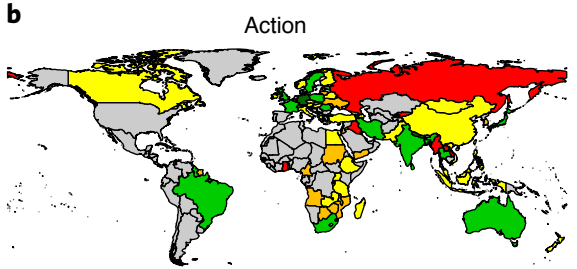

Agrobiodiversity in consumption

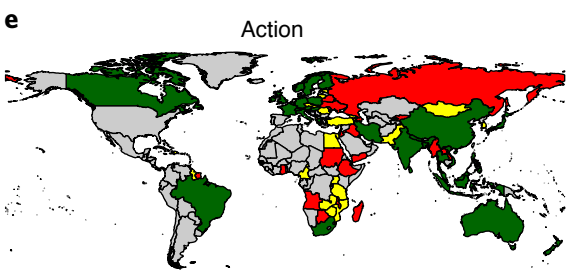

Agrobiodiversity in production

h

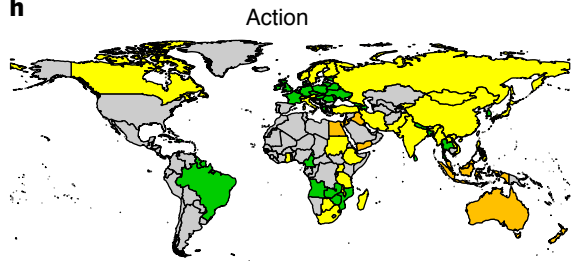

Agrobiodiversity in conservation
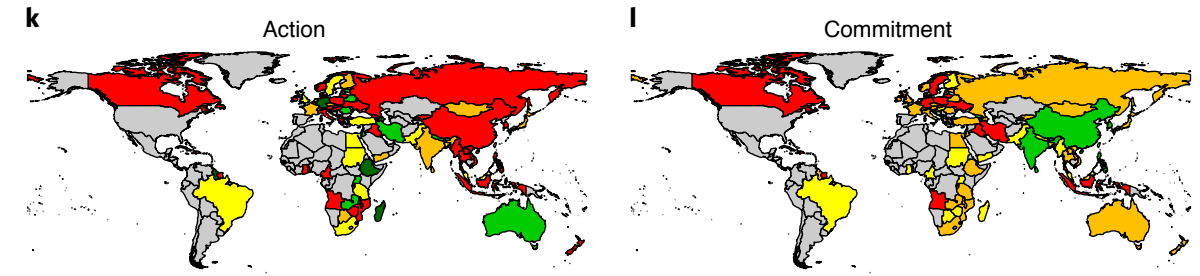

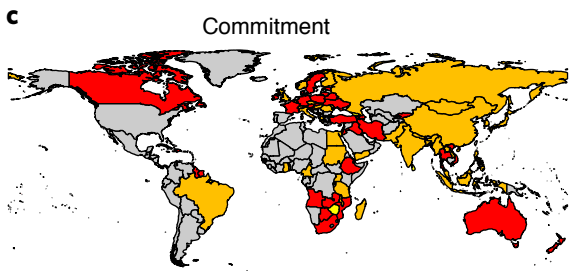

f

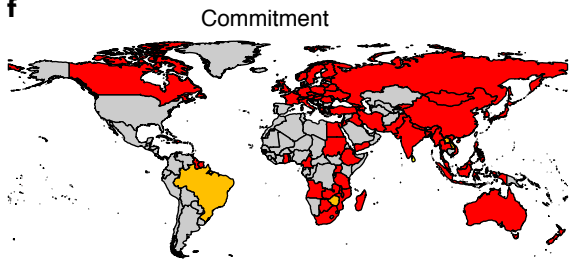

i

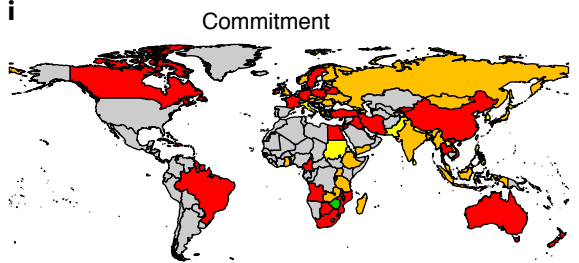

0

20

40

60

80

100

Fig. 2 | ABDI scores for $\mathbf{8 0}$ countries. a-I, Maps showing status, action and commitment scores for the whole food system (a-c) and disaggregated to show how agrobiodiversity varies in consumption ( $\mathbf{d - f}$ ), production ( $\mathbf{g}-\mathbf{i}$ ) and conservation (j-I). The scores range from 0 (least desirable) to 100 (most desirable). The colours indicate where scores are very low (0-20, red), low (21-40, orange), moderate (41-60, yellow), high (61-80, green) or very high (81-100, dark green). Countries that were not included in the analysis are shown in grey.

this result can be interpreted as showing that the adoption of management practices supporting agrobiodiversity in production needs upscaling in most countries in our analysis, assuming that organic and conservation agriculture should be adopted on all arable land, tree cover on agricultural land should be at least $30 \%$, nitrogen use efficiency and yields should be maximized, and pesticide use should be reduced to zero. Scores are low (although globally highly variable) for management practices supporting agrobiodiversity in conservation for future use options $(\mu=30.2$, s.d. =30.7). This reveals that on average, countries report on only $30 \%$ of the 80 action-related indicators in the World Information and Early Warning System on Plant Genetic Resources for Food and Agriculture, although this ranges from $0 \%$ of indicators reported by 49 countries to $44 \%$ reported by Brazil. Concerted efforts from all regions to improve national reporting on World Information and Early Warning System indicators would help close the gap in the global monitoring of plant genetic resources.
Commitment indicator scores reveal that most countries have made no or only weak political commitments to enhancing the use of agrobiodiversity in consumption, on the basis of an analysis of National Biodiversity Strategies and Action Plans (NBSAPs). This result highlights that political support for diet- and market-led agrobiodiversity conservation could be better considered in the global biodiversity conservation agenda. In production, most countries made their strongest commitments to enhancing varietal diversity, species diversity, pollinators and natural enemies of pests, landscape complexity, and overall agrobiodiversity (for example, including commitments to increased adoption of organic agriculture and agroecological practices). Very few commitments have been made to enhancing functional diversity, soil biodiversity or underutilized species in production. In conservation, most countries have made commitments to safeguard overall agrobiodiversity, varietal diversity, species diversity and underutilized species. Almost no countries have made commitments to conserve functional diversity, pointing 
Table 2 | ABDI scoreboard

\begin{tabular}{|c|c|c|c|c|c|c|c|c|}
\hline \multicolumn{2}{|c|}{ Whole food system } & \multicolumn{2}{|l|}{ Per pillar } & \multicolumn{2}{|l|}{ Per indicator } & \multicolumn{3}{|l|}{ Per sub-indicator } \\
\hline Category & Mean & Pillar & Mean & Indicator & Mean & Sub-indicator & Mean & s.d. \\
\hline \multirow[t]{16}{*}{ Status } & \multirow[t]{16}{*}{56} & \multirow[t]{3}{*}{ Consumption } & \multirow[t]{3}{*}{69.9} & Species diversity & 57.4 & Food diversity in diets & 57.4 & 17.4 \\
\hline & & & & Functional diversity & 67.8 & Avoided disability-adjusted life years & 67.8 & 15.5 \\
\hline & & & & Underutilized species & 84.4 & $\begin{array}{l}\text { Energy from sources other than cereals and } \\
\text { starches }\end{array}$ & 84.4 & 18.6 \\
\hline & & \multirow[t]{8}{*}{ Production } & \multirow[t]{8}{*}{49.4} & Varietal diversity & 51 & Livestock breed diversity & 51 & 23.9 \\
\hline & & & & \multirow[t]{5}{*}{ Species diversity } & \multirow[t]{5}{*}{60.4} & Percentage of diversified cropland & 72.9 & 27.4 \\
\hline & & & & & & Crop species diversity in production & 60.2 & 13.8 \\
\hline & & & & & & Species richness in production & 44.7 & 15.8 \\
\hline & & & & & & $\begin{array}{l}\text { Freshwater fish species richness per major } \\
\text { sub-basin }\end{array}$ & 67.3 & 32.9 \\
\hline & & & & & & Species diversity of livestock in production & 57.1 & 15.2 \\
\hline & & & & Soil biodiversity & 44.8 & Potential soil biodiversity index & 44.8 & 19.1 \\
\hline & & & & Landscape complexity & 41.5 & $\begin{array}{l}\text { Cropland with at least } 10 \% \text { natural } \\
\text { vegetation }\end{array}$ & 41.5 & 19.5 \\
\hline & & \multirow[t]{5}{*}{ Conservation } & \multirow[t]{5}{*}{48.6} & Varietal diversity & 57.9 & Varietal diversity in gene bank accessions & 57.9 & 23.1 \\
\hline & & & & \multirow[t]{2}{*}{ Species diversity } & \multirow[t]{2}{*}{57.2} & Crop wild relative species diversity & 58.2 & 14.3 \\
\hline & & & & & & Species diversity in gene bank accessions & 56.3 & 19.5 \\
\hline & & & & \multirow[t]{2}{*}{ Underutilized species } & \multirow[t]{2}{*}{30.7} & In situ conservation representativeness & 59.9 & 26.3 \\
\hline & & & & & & Ex situ conservation representativeness & 1.5 & 1.5 \\
\hline \multirow[t]{9}{*}{ Action } & \multirow[t]{9}{*}{47.8} & \multirow[t]{2}{*}{ Consumption } & \multirow[t]{2}{*}{56.2} & $\begin{array}{l}\text { Management } \\
\text { practices supporting }\end{array}$ & 56.2 & $\begin{array}{l}\text { Policies or guidelines leading to diverse } \\
\text { diets }\end{array}$ & 55 & 50.1 \\
\hline & & & & & & $\begin{array}{l}\text { Resources to facilitate the uptake of diverse } \\
\text { diets }\end{array}$ & 57.5 & 49.7 \\
\hline & & Production & 57.1 & $\begin{array}{l}\text { Diversity-based } \\
\text { practices }\end{array}$ & 76.7 & $\begin{array}{l}\text { Diversification through crop-livestock } \\
\text { systems }\end{array}$ & 76.7 & 22.8 \\
\hline & & & & Management & 37.4 & Integrated plant nutrient management & 41.2 & 20.1 \\
\hline & & & & practices supporting & & Organic agriculture & 1.1 & 3.5 \\
\hline & & & & & & Tree cover on agricultural land & 53.6 & 30.8 \\
\hline & & & & & & $\begin{array}{l}\text { Avoided overuse of chemical control } \\
\text { mechanisms }\end{array}$ & 88.5 & 21 \\
\hline & & & & & & Conservation agriculture & 2.8 & 8.6 \\
\hline & & Conservation & 30.2 & $\begin{array}{l}\text { Management } \\
\text { practices supporting } \\
\text { agrobiodiversity }\end{array}$ & 30.2 & $\begin{array}{l}\text { International reporting on plant genetic } \\
\text { resources for food and agriculture }\end{array}$ & 30.2 & 30.7 \\
\hline Commitment & 21.4 & Consumption & 4.4 & Commitments & 4.4 & Overall agrobiodiversity & 2.9 & 13.2 \\
\hline & & & & supporting & & Varietal diversity & 2.9 & 10.9 \\
\hline & & & & & & Species diversity & 8.3 & 18.8 \\
\hline & & & & & & Functional diversity & 5.8 & 14.8 \\
\hline & & & & & & Underutilized species & 2.1 & 13.4 \\
\hline & & Production & 23.5 & Commitments & 23.5 & Overall agrobiodiversity & 44.6 & 33.5 \\
\hline & & & & $\begin{array}{l}\text { supporting } \\
\text { agrobiodiversity }\end{array}$ & & Varietal diversity & 25.8 & 27 \\
\hline & & & & & & Species diversity & 35.4 & 28.7 \\
\hline & & & & & & Functional diversity & 5 & 16 \\
\hline & & & & & & Underutilized species & 5.8 & 17.4 \\
\hline & & & & & & Pollinators and natural enemies & 26.2 & 21.7 \\
\hline & & & & & & Soil biodiversity & 7.5 & 17.6 \\
\hline & & & & & & Landscape complexity & 37.5 & 35.7 \\
\hline & & Conservation & 36.2 & Commitments & 36.2 & Overall agrobiodiversity & 74.2 & 25.4 \\
\hline & & & & supporting & & Varietal diversity & 28.3 & 31.9 \\
\hline & & & & & & Species diversity & 42.9 & 26.6 \\
\hline & & & & & & Functional diversity & 0.4 & 3.7 \\
\hline & & & & & & Underutilized species & 35.4 & 32.4 \\
\hline
\end{tabular}

Mean scores and standard deviations across 80 countries. The raw sub-indicator scores for each country were linearly transformed to a scale from 0 (least desirable) to 100 (most desirable). These sub-indicator scores were aggregated into indicator scores. The indicator scores were aggregated to provide status, action and commitment scores in consumption, production and conservation. The pillar scores were aggregated to provide scores for the whole food system. See Supplementary Table 1 for details on the data sources and scaling thresholds. 
to a potential risk of insufficient action to conserve cultivars with unique nutritional, agronomic or ecological traits to enhance future adaptive capacity ${ }^{32}$.

Scores by region and development status. We classified countries by United Nations development level and geographic region to identify clusters of countries with similar ABDI scores. There were no significant inter-regional differences in status scores for agrobiodiversity in production (Supplementary Tables 6 and 8-13). For example, we found that agrobiodiversity status scores in production were above average in some arid countries (such as Mongolia) and below average in some tropical countries (such as Rwanda). There were significant differences in scores for the status of agrobiodiversity in consumption and conservation across regions. For example, the Americas and Europe had significantly higher scores than Africa and Asia for the status of agrobiodiversity in consumption, suggesting that the former regions have access to higher levels of agrobiodiversity for healthy diets. Conversely, Africa and Asia had significantly higher scores than the Americas and Europe for commitments to agrobiodiversity in conservation, indicating that these regions are driving the integration of agrobiodiversity into policy to meet global conservation agendas.

While agrobiodiversity status in production was moderate across all countries grouped by development status, agrobiodiversity status in consumption and conservation was significantly higher in developed countries ( $\mu=78.0$ and $\mu=60.5$ for consumption and conservation, respectively) than in developing ( $\mu=68.7$ and $\mu=45.4)$ and least developed countries $(\mu=57.3$ and $\mu=33.1)$ (Supplementary Tables 7-13). This suggests that priority should be given to enhancing the use and conservation of agrobiodiversity for healthy diets and future use options in developing countries, while countries at all development levels should continue to make efforts to improve agrobiodiversity levels in production.

Opportunities to enhance agrobiodiversity. Countries with very high $(>80)$ status, action and commitment scores might be considered to be in an ideal position, since agrobiodiversity levels in the food system are relatively high with actions being taken to maintain or enhance these levels, and there is political support to ensure that actions continue. No countries in our analysis achieved this ideal. Twelve countries (Albania, Australia, Brazil, Croatia, France, Germany, Japan, Poland, Romania, South Africa, Switzerland and the United Kingdom) have high $(>60)$ or very high $(>80)$ scores for both status and action, while falling short on commitments, where scores are low or very low (Fig. 3). Among the remaining countries, 48 have higher status than action scores, flagging a risk that agrobiodiversity levels will deteriorate due to insufficient actions to maintain them. In contrast, countries with low or moderate status scores coupled with high or very high action scores include many Asian countries, such as Bangladesh, India, Iran, Nepal and Sri Lanka. Sri Lanka, India and Nepal are also among the ten countries with the strongest commitments to enhancing agrobiodiversity for sustainable food systems. These countries are not currently making full use of agrobiodiversity for food system sustainability, yet they have already taken actions or published policies that could enhance its contribution.

Relationship between dimensions of agrobiodiversity. There were low levels of intercorrelation among indicators and between sub-indicators, suggesting that distinct measurements were complementary with a low level of redundancy (Supplementary Figs. 3-5). Of note, there was a moderate positive correlation between presence/absence of dietary guidelines and reduced dietary risks, and a weak correlation between presence/absence of food composition tables and reduced dietary risks (Spearman's rank correlation, $\rho=0.49$ and $\rho=0.38$, respectively; $P<0.05$ ), suggesting that dietary recommendations and food composition tables are indeed linked to healthy diets.

\section{Discussion}

Priorities to enhance agrobiodiversity. On the basis of 80 countries and 17 indicators, we found that mean ABDI status and action scores were moderate and commitment scores were low. Globally, there is potential to substantially enhance levels of agrobiodiversity for more sustainable and diverse food systems. Improving the status of agrobiodiversity in production and conservation systems emerged as the highest priorities, on the basis of mean status scores. Enhancing agrobiodiversity through practices such as agroforestry has co-benefits for multiple ecosystem services ${ }^{12,33}$, as do integrating natural vegetation into agricultural landscapes ${ }^{34-36}$ and practicing organic or conservation agriculture ${ }^{37,38}$. We found that the implementation of these interventions is low in most countries, highlighting an apparent gap between empirical evidence and land manager decisions. Increasing diversity and favouring supportive management practices in production systems are even more relevant in the context of COVID-19, which has reminded us of the importance of diversified, resilient, localized production systems to maintain animal, human and ecological health ${ }^{39,40}$.

In conservation, our results reiterate the concerningly low levels of ex situ conservation of crop wild relatives and other useful wild plants in all countries ${ }^{27,28}$. Safeguarding food genetic resources in situ and ex situ is directly beneficial to global biodiversity conservation goals and is critical for breeding improved varieties of edible plants to help farmers adapt to climate variation, pests and diseases and fill nutritional gaps ${ }^{28,41,42}$.

Actions and commitments could be strengthened across all parts of the food system to accelerate the transition to maximizing agrobiodiversity's contribution to food system sustainability. Commitment scores were derived from policies written into NBSAPs, whose focus is on biodiversity conservation of genetic resources. Nonetheless, consistently low scores highlight that targets for enhancing biodiversity in consumption and production should be clearly incorporated into the Convention on Biological Diversity (CBD) post-2020 global biodiversity framework to encourage countries to take action for safeguarding agrobiodiversity by making better use of the vast number of species and varieties available for human consumption ${ }^{22}$. Commitments and actions to enhance agrobiodiversity need to be taken early on because they will take time to translate into changes in status due to political, social and ecological contexts ${ }^{43}$.

Agrobiodiversity potential. Sub-indicator scores in the ABDI are classified as high or low on the basis of minimum and maximum thresholds set by the user. For the status sub-indicators, these thresholds would ideally be used to discuss how near or far agrobiodiversity levels are from their potential contribution to improving food system sustainability. Yet, the 'real' potential of agrobiodiversity is generally unknown, just as it is for other types of biodiversity ${ }^{44}$. Here, we used the same thresholds for all countries in the analysis, which builds on the assumption that all countries can achieve the same maximum levels of diversity in food and agriculture. This decision was made partly because agrobiodiversity will not necessarily follow the same diversity patterns as those of other plants and animals. Since agrobiodiversity is a product of human-environment interactions, levels of agrobiodiversity depend on socio-cultural practices, technological and financial resources, trade flows, institutional contexts, and biotic and abiotic factors $^{45}$. It is therefore very difficult to determine context-specific thresholds, and indeed these have not been proposed as far as we know for any of the agrobiodiversity measures in our application. The decision was also data-driven: many of our input datasets were from FAO, which records consumption and production levels 

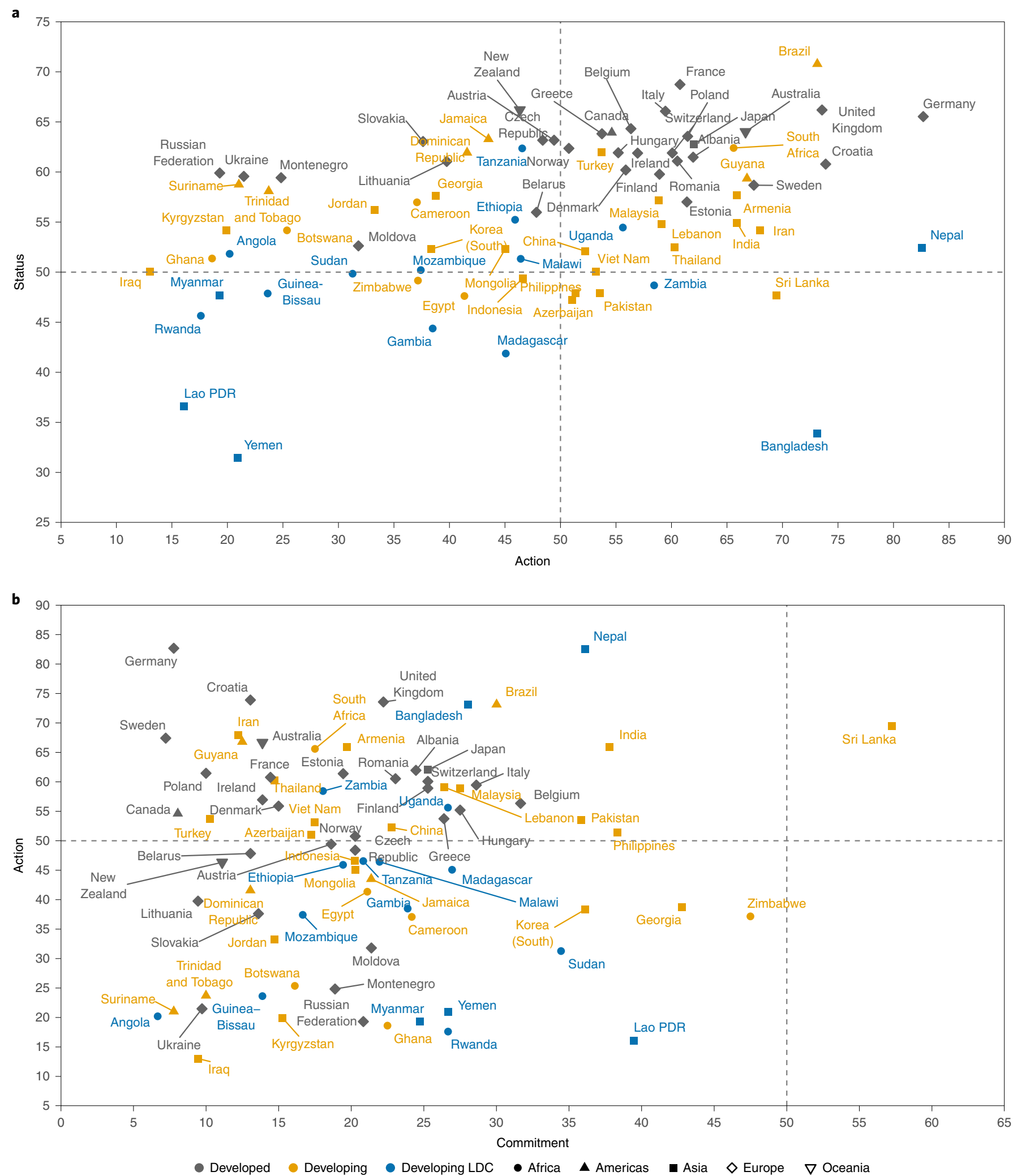

Fig. 3 | Country score comparisons. a,b, Scatterplots showing country ABDI status and action scores (a) and action and commitment scores (b). Point shape and colour indicate country region and development status, respectively. Note that the axes have varying scales. LDC, least developed country.

for only a limited number of crops, livestock and fish, and a high diversity of these plants and animals should be achievable in all countries. However, our approach to setting thresholds can certainly be improved, such as through future in-depth studies to identify options for applying context-specific thresholds for each type of agrobiodiversity. 
Limitations and critical data gaps. In building composite indicators, there is a trade-off between the number of indicators included and the number of countries that can be assessed ${ }^{46,47}$. While using fewer input datasets would have allowed us to assess more countries, we sought to balance breadth and depth and ensure that a wide range of both food system components and countries were included in the analysis. However, the full potential of the ABDI is limited by data availability and resolution. For example, we were not able to find consistent global data on many relevant actions to enhance agrobiodiversity in consumption (such as national healthy eating campaigns or regulations to maintain diversity in school meals) or in production (such as the uptake of intercropping or the use of cover crops or cultivar mixtures). In addition, many of the indicators in this paper relied on data from FAO, which are limited to what countries report and are not always disaggregated to enable detailed analyses. Indicators dependent on national reporting will favour countries with better monitoring and reporting systems and with less reliance on under-represented elements of agrobiodiversity, such as local and wild species, which can constitute a major part of the food system diversity in rural areas ${ }^{48}$. This may partly explain why some temperate developed countries had higher agrobiodiversity status scores in this study, while some tropical, less developed countries had low agrobiodiversity status scores. Concerted international data collection and reporting efforts are needed to help fill critical data gaps. Due to language constraints and for consistency, we restricted our analysis to the 80 countries that submitted English versions of their NBSAPs to the CBD, and for which data were available across all selected sub-indicators. This means that some major food-producing countries, including the United States (no NBSAP submitted), and some countries with high native agrobiodiversity, such as Peru, Argentina and the Congo, were not included despite data being available for some indicators in these countries. Data for the excluded countries are available online (see the 'Data availability' section). Future work to expand the commitments analysis to non-English-speaking countries and a wider range of policy documents would allow for a more comprehensive global analysis.

An operational index for food system actors and biodiversity targets. The value of the ABDI is that it highlights where a lack of agrobiodiversity might make it more challenging for countries to achieve healthy diets, environmental sustainability in production and food systems that are resilient to climate change and other stressors. Conversely, it shows where focusing efforts to enhance agrobiodiversity can facilitate achieving these outcomes. The data collated for our application of the ABDI are globally and freely available. The approach therefore represents a fast, practical method for countries to investigate the state of their agrobiodiversity and evidence of actions to use and conserve it. This information can be used to help identify which measurable dimensions of agrobiodiversity (for example, neglected and local crops or livestock richness) could be better integrated into conservation policies and promoted for use in production and markets. Many national-level agrobiodiversity datasets used in this paper are available on a repeat basis and can be used to help track progress towards global biodiversity conservation targets for the post-2020 Global Biodiversity framework of the CBD at national, regional and global levels. Other datasets, metrics and scaling thresholds could be used to improve the usefulness and validity of the ABDI scores for specific applications and local contexts. For example, the index could be applied at the subnational level where data are available, and thresholds for the highest and lowest agrobiodiversity for each sub-indicator could be set by local agrobiodiversity experts to match locally relevant targets. Through the ABDI, agrobiodiversity data can be consistently collated and used to trigger policy dialogue and guide decision-making and research agendas towards enhancing agrobiodiversity's contribution in the global transformation to sustainable food systems.

\section{Methods}

Overview of the ABDI. The ABDI has been under development since 2017 under the leadership of Bioversity International (now in Alliance with the International Center for Tropical Agriculture) in collaboration with many stakeholders, including country, private sector, development agency and non-governmental organization representatives. Scientific evidence for the role of agrobiodiversity in contributing to sustainable food systems was synthesized into a book in 2017 by Bioversity International ${ }^{49}$, which provided the foundations for the ABDI. ABDI development accelerated in 2018, leading to the publication of the provisional ABDI methodology in an institutional report ${ }^{50}$. This report presented a core set of 22 indicators to monitor agrobiodiversity in sustainable food systems, for countries, companies and projects, and proposed an approach for indicator weighting and aggregation into composite scores. Development decisions were guided by scientific evidence and end-user needs, on the basis of literature reviews (for example, of indicator aggregation approaches ${ }^{50}$ ), data exploration (for example, the sensitivity of ABDI scores to applying indicator weights ${ }^{50}$ ) and consultation with public and private stakeholders and food system experts. The process included regular consultation with members of an Expert Review Committee and Advisory Panel, who advised on methodological improvements, communication of results and priority applications. In addition, the ABDI methodology and provisional results for different applications were presented at over 50 scientific, agribusiness and policy engagement events and meetings between 2017 and 2020. Feedback and suggestions from all stakeholder groups received during or after these events were used to improve the ABDI methodology and messaging.

The ABDI includes a minimal set of 22 indicators (Table 1 ) designed to capture the most important dimensions of agrobiodiversity contributing to food system sustainability ${ }^{49}$ (Table 1). These indicators are organized into three pillars that describe key functions of agrobiodiversity in our food systems: agrobiodiversity in consumption, contributing to healthy diets (pillar 1); agrobiodiversity in production, contributing to sustainable agriculture (pillar 2); and agrobiodiversity in genetic resource conservation, contributing to current and future use options (pillar 3). Across the three pillars, the indicators are further organized into three measurement categories: status, action and commitment. Status indicators (15 indicators) assess the level of agrobiodiversity (for example, in terms of Shannon's diversity index or richness) in a country as presented here, but their application can be extended to assessing company portfolios or project footprints. Action indicators ( 4 indicators) focus on tracking implemented interventions to enhance agrobiodiversity levels. Commitment indicators (3 indicators) measure the level of support for enhancing agrobiodiversity levels expressed in public policies and codes of conduct. These commitments may or may not have been transformed into actual interventions.

The ABDI indicators were selected on the basis of extensive consultation with stakeholders from public and private sectors, research institutes and academia ${ }^{50}$. Four indicators aim at capturing the different ways that food diversity in consumption contributes to healthy diets. Seven indicators measure the diversity of plants, animals and microorganisms in production where these contribute to making agriculture environmentally sustainable. In the conservation pillar, four indicators measure the diversity of genetic resources in conservation where these contribute to safeguarding current and future use options. For action and commitments, the ABDI separates indicators across the three pillars, since often very different management actions and political commitments influence the status of agrobiodiversity in consumption, production and conservation. In the production pillar, two action indicators are used to distinguish diversity-based practices (for example, crop diversification and maintenance of landscape complexity) from management practices (for example, integrated pest management and conservation agriculture) supporting agrobiodiversity, following the classification of practices described in the FAO guidelines on country reporting for the State of the World's Biodiversity for Food and Agriculture reports ${ }^{51}$

ABDI approach. Applying the ABDI involves selecting appropriate datasets for the 22 indicators, calculating sub-indicator scores and aggregating these scores into composite measures to enable the exploration of different types and levels of agrobiodiversity across the food system (Fig. 1). The most suitable datasets to use for each of the 22 indicators in the ABDI will depend on the study's objective and unit of analysis. In all cases, the data should be selected on the basis of a clear set of quality criteria. Typical data sources include scientific literature, research institutes, international organizations and government agencies. Typical data formats for status and action indicators include remotely sensed data, in-field measurements and surveys, and government statistics. For action indicators, data formats may also include reports or online platforms documenting interventions completed to manage agrobiodiversity. Data for commitment indicators can be compiled through a systematic review of multiple policy documents using a transparent and rigorous methodology. For this purpose, we developed a methodology which comprises the following steps: (1) selecting relevant policy documents, (2) performing a keyword search to identify agrobiodiversity-related text and (3) analysing each text extract and scoring the level of commitment using a standard scoring scheme. The documents selected for step 1 should ideally include all active policies on nutrition, food, agriculture and ecosystem management, and food genetic resources. For step 2, we developed a keyword 
list of agrobiodiversity-related search terms through a review of peer-reviewed and institutional literature, first published in 2018 (ref. ${ }^{50}$ ). This list was improved by adding and removing keywords through a series of validation workshops held between 2018 and 2020, each including at least six Bioversity International scientists with expertise spanning nutrition, sustainable production, food genetic resources and ontologies. The process of searching each policy document for keyword occurrences can be very time-consuming ${ }^{52}$. The ABDI team developed a Python text-mining script to automate this process, first described in Juventia et al..$^{52}$. The script uses natural language processing tools to identify and extract into a spreadsheet passages of text containing any of the agrobiodiversity-related keywords. For step 3, we developed guidelines for consistently scoring these text extracts using a simple three-level classification, whereby text that mentions agrobiodiversity scores 1 , text that contains an explicit strategy to enhance the use or conservation of agrobiodiversity scores 2 , and text that contains a time-bound target to enhance the use of conservation of agrobiodiversity scores 3 . These guidelines, the keyword list and examples of text at each score level are provided in the Supplementary Methods.

Once the datasets have been identified, sub-indicator scores are computed by selecting appropriate measures and thresholds for scaling need to be defined. Measures refer to the units (for example, hectare) and scale (for example, area of arable land) of measurement that will be used to summarize the data into a single comparable value per country or other unit of analysis. This value is referred to as the raw sub-indicator score. Minimum and maximum thresholds need to be set to scale the raw sub-indicator scores from 0 to 100 by applying a linear transformation ${ }^{53}$ using equation (1):

$$
\text { Sub-indicator score }=100 \times \frac{X-\min (X)}{\max (X)-\min (X)}
$$

where $X$ is the raw sub-indicator value, and $\min (X)$ and $\max (X)$ are the thresholds set for each sub-indicator. The directionality of each sub-indicator score must be aligned by multiplying each by +1 or -1 so that higher values represent positive impacts and lower values represent negative impacts on food system sustainability. Threshold selection plays a key role in determining the final scores and should be based on scientific evidence or, in the absence of evidence, following normative rules.

Weighting and aggregation methods are critical steps in designing composite indicators ${ }^{54,55}$. Following recommendations to use equal weighting when indicators are considered equally important ${ }^{56}$, we do not currently recommend applying weights to sub-indicators (or indicators) in the ABDI. We conducted a sensitivity analysis on national-level data compiled for ten countries, which showed that overall status, action and commitment scores were robust to changes in individual sub-indicator weights ${ }^{50}$. This suggests that no single input dataset had a disproportionally large effect on the overall scores, providing further support for the decision not to apply weights.

The ABDI provides a set of composite scores designed to help end users understand agrobiodiversity levels and management in different parts of the food system. These composite scores are obtained using a simple unweighted additive approach ${ }^{57}$. The first level of aggregation is to the indicator level, whereby sub-indicator scores (scaled from 0 to 100) related to a single indicator are aggregated by taking the arithmetic mean. This provides scores for the 22 agrobiodiversity indicators. The second level of aggregation is to the pillar level (consumption, production and conservation) within each measurement category (status, action and commitment). Indicators in the same pillar and measurement category are aggregated by again taking the arithmetic mean, to provide nine scores corresponding to agrobiodiversity status, action and commitment scores, for each for the three pillars. At the final level, the scores are aggregated by taking the arithmetic mean of the pillar scores to provide three scores that represent agrobiodiversity status, action and commitment scores across the whole food system.

The benefit of this aggregation approach is that it is simple and therefore easy to communicate to end users ${ }^{54}$. This may be one of the reasons why it is widely used in composite sustainability indicators, such as the Human Development Index ${ }^{57}$. However, the approach implicitly assumes that sub-indicators within an indicator are substitutable ${ }^{54}$, and status (or action or commitment) indicators within consumption, production and conservation are also substitutable. For example, for the status indicator on species diversity in production, lower levels of crop species diversity can be countered by higher levels of livestock species diversity. Although the highest (and lowest) scores will still be achieved only if both sub-indicators score 100 (or 0), ensuring that these extreme indicator scores are robust, sub-indicator substitutability is assumed between the extremes. This is problematic since taking (non-extreme) aggregated scores at face value could lead to misguided decisions on what to prioritize to enhance agrobiodiversity's contribution to food system sustainability. It is for this reason that we provide the full breakdown of scores at each aggregation level. While this does not overcome the limitations of the additive aggregation approach, it provides full transparency to aid interpretation.

Global application. Data. For the global analysis presented in this paper, we searched scientific literature and official databases for global datasets suitable for populating each of the $22 \mathrm{ABDI}$ indicators. Datasets were selected for inclusion on the basis of their: (1) relevance (that is, the data contain information related to one of the indicators in the ABDI), (2) methodological robustness (that is, the data collection method is clearly documented and applied consistently), (3) scientific credibility (that is, the data are validated in peer-reviewed publications or the data are sourced through official repositories), (4) comparability (that is, the data units and coverage are comparable across space or time), (5) completeness (that is, including only datasets covering at least 100 countries), (6) recency (prioritizing newer datasets and excluding data collected pre-2000) and (7) accessibility (prioritizing publicly available datasets to increase transparency). If no datasets met these data selection criteria for a given indicator, the indicator was excluded from the analysis.

We identified 16 datasets for status indicators that met the data selection criteria (Supplementary Table 1). The selected datasets covered 10 of the 15 status indicators. No suitable datasets were identified for five indicators for the status of varietal diversity in consumption; underutilized species, functional diversity, and pollinators and natural enemies in production; or functional diversity in conservation. The selected datasets included six remotely sensed or statistically extrapolated spatial datasets $(1 \mathrm{~km} \times 1 \mathrm{~km}$ or $10 \mathrm{~km} \times 10 \mathrm{~km})$, four sourced directly from FAOSTAT, two from accession data in Genesys, two from crop wild relative data compiled by Khoury et al. ${ }^{27}$ and two from other sources. We selected units and scales of measurement that could be meaningfully compared across countries, using continuous scales wherever possible. We used Shannon's diversity index ${ }^{30}$ to compute diversity scores, such as from data on the proportion of cropped area, livestock population counts and crop wild relative occurrences.

For action indicators, we identified nine suitable datasets providing information on all four indicators. The selected datasets included two statistically extrapolated datasets $(1 \mathrm{~km} \times 1 \mathrm{~km}$ or $10 \mathrm{~km} \times 10 \mathrm{~km})$, five datasets compiled by FAOSTAT and two from other sources. As with the status datasets, we sought to compare data across countries using continuous scales of measurement where possible. Some datasets already contained information in suitable formats, such as organic land as a percentage of total arable land. Where this was not the case, we converted the data to proportions or other comparable measures (Supplementary Methods)

For the analysis of commitments to agrobiodiversity, we sourced data from the 119 NBSAPs available in English in the CBD repository (https://www.cbd.int/ nbsap/search/, accessed 6 April 2020). We limited the analysis to English-language NBSAPs to ensure that the extracted data could be analysed and cross-checked by at least two team members. We decided not to include other potentially relevant policies, such as those on nutrition available from the Global database on the Implementation of Nutrition Action, because the number of English text documents related to these different policy sectors was highly uneven across countries. We used the most recent NBSAP available for each country and applied the ABDI text-mining script to automatically identify and extract sentences containing a predefined list of 199 agrobiodiversity-related keywords (the full keyword list is provided in Supplementary Table 5), together with the sentence before and after. Each group of sentences extracted was read manually and assigned a score of 0 (not relevant), 1 (agrobiodiversity mentioned only), 2 (strategy set) or 3 (target set) on the basis of the strength of commitment to agrobiodiversity use and conservation, using pre-defined guidelines (Supplementary Table 4). Each commitment was categorized into one of the 18 sub-indicators representing different dimensions of agrobiodiversity across the three pillars. The highest commitment score within a single sub-indicator determined the sub-indicator score.

For status, action and commitment sub-indicators, the raw scores were scaled from 0 to 100 using the same thresholds for all countries in the analysis. We set minimum and maximum thresholds for data values on the basis of theoretical limits for most sub-indicators (for example, 0 and 100 for per cent organic agriculture). In some cases, including where there were no theoretical limits, the thresholds were based on the cross-country data minimums and maximums. Thresholds were altered if there was a sound scientific justification-for example, for per cent tree cover on agricultural land, we set a maximum threshold of $30 \%$ since $100 \%$ tree cover would make the production of most crops impossible, and $30 \%$ is noted as an approximate cut-off to maintain reasonable yields for crops well adapted to tree cover (such as cocoa) ${ }^{58}$. Supplementary Table 1 provides the data sources and scaling thresholds used for all sub-indicators. Additional details including data processing steps for each sub-indicator are provided in the Supplementary Methods.

Only those countries that had complete data across all selected status, action and commitment sub-indicators were retained for the final analysis. The final dataset contained complete data for 80 countries across 43 sub-indicators corresponding to $17 \mathrm{ABDI}$ indicators. This included data for 10 of the 15 status indicators and all action and commitment indicators.

Analysis. We aggregated the sub-indicator scores using the ABDI methodology. We checked for differences between mean region and development group ABDI status, action and commitment scores in consumption, production and conservation, grouping countries using the United Nations standard divisions for statistical application ${ }^{59}$. For status and action scores in production and conservation, which were normally distributed across the 80 countries, we tested for significance at the 
$95 \%$ confidence level using one-way analysis of variance. Tukey's test was used to identify which groups were significantly different, using the agricolae package in $\mathrm{R}^{60}$. For commitment scores and for status and action scores in consumption, cross-country scores did not meet tests for normality. We therefore applied Kruskal-Wallis, followed by Dunn's test, to check for significant differences between countries grouped by region and development levels, using the dunn.tes package in $\mathrm{R}^{61}$

Finally, we explored correlations between ABDI scores. Correlations between action and status categories may reveal associations between interventions and changes in outcomes for agrobiodiversity. For example, higher crop diversity in production may be associated with higher species diversity in consumption. Similarly, correlations between commitments and action scores may reveal associations between policies and the adoption of practices supporting agrobiodiversity. Correlations can also highlight redundancies between conceptually related sub-indicators, in which case one of the sub-indicators should be removed. We used Spearman's rank correlation to test the strength of correlations between country status, action and commitment scores, using a 95\% confidence level. Spearman's rank correlation does not require data to be normally distributed and is therefore more suitable than Pearson's product moment to test correlations if some variables do not meet normality assumptions ${ }^{62}$, as was the case for consumption and commitment scores in our dataset. All data processing and analysis was done in $\mathrm{R}^{63}$

\section{Data availability}

Supplementary Table 1 provides full references to all datasets used in the manuscript. ABDI scores for every country included in our global analysis are accessible from Dataverse ${ }^{64}$

\section{Code availability}

Text mining of policy documents was conducted using pdftotext v.4.01, the Textract library in Python v.3.0 and the Tesseract optical character recognition tool (custom code). The custom code used for text mining is available at https:/ github.com/marieALaporte/commitment-score. The custom code used for status and action data processing is available at https://github.com/skatejones/ AgrobiodiversityIndex.

Received: 15 July 2020; Accepted: 14 July 2021; Published online: 6 September 2021

\section{References}

1. Living Planet Report 2020: Bending the Curve on Biodiversity Loss (WWF, 2020).

2. Routledge Handbook of Agricultural Biodiversity (Routledge, 2017).

3. Ulian, T. et al. Unlocking plant resources to support food security and promote sustainable agriculture. Plants People Planet 2, 421-445 (2020)

4. Jarvis, D. I. et al. A global perspective of the richness and evenness of traditional crop-variety diversity maintained by farming communities. Proc. Natl Acad. Sci. USA 105, 5326-5331 (2008).

5. The State of the World's Biodiversity for Food and Agriculture (FAO Commission on Genetic Resources for Food and Agriculture, 2019); https://doi.org/10.4060/ ca3129en

6. Soroye, P., Newbold, T. \& Kerr, J. Climate change contributes to widespread declines among bumble bees across continents. Science 367, 685-688 (2020).

7. Willett, W. et al. Food in the Anthropocene: the EAT-Lancet Commission on healthy diets from sustainable food systems. Lancet 393, 447-492 (2019).

8. Lachat, C. et al. Dietary species richness as a measure of food biodiversity and nutritional quality of diets. Proc. Natl Acad. Sci. USA 115, 127-132 (2018)

9. Afshin, A et al. Health effects of dietary risks in 195 countries, 1990-2017: a systematic analysis for the Global Burden of Disease Study 2017. Lancet 393, 1958-1972 (2019).

10. Altieri, M. A. \& Nicholls, C. I. Biodiversity and Pest Management in Agroecosystems (Food Products, 2004).

11. McDaniel, M. D., Tiemann, L. K. \& Grandy, A. S. Does agricultural crop diversity enhance soil microbial biomass and organic matter dynamics? A meta-analysis. Ecol. Appl. 24, 560-570 (2014).

12. Beillouin, D., Ben-Ari, T. \& Makowski, D. Evidence map of crop diversification strategies at the global scale. Environ. Res. Lett. 4, 123001 (2019).

13. Stomph, T. J. et al. Designing intercrops for high yield, yield stability and efficient use of resources: are there principles? Adv. Agron. 160, 1-50 (2020).

14. Raseduzzaman, M. \& Jensen, E. S. Does intercropping enhance yield stability in arable crop production? A meta-analysis. Eur. J. Agron. 91 , 25-33 (2017).

15. Renard, D. \& Tilman, D. National food production stabilized by crop diversity. Nature 571, 257-260 (2019).

16. International Food Policy Research Institute. Global spatially-disaggregated crop production statistics data for 2010 version 1.1. Harvard Dataverse v.3 (Harvard Dataverse, 2019).
17. You, L., Wood, S., Wood-Sichra, U. \& Wu, W. Generating global crop distribution maps: from census to grid. Agric. Syst. 127, 53-60 (2014)

18. Tedesco, P. A. et al. Data Descriptor: a global database on freshwater fish species occurrence in drainage basins. Sci. Data 4, 170141 (2017).

19. Sibhatu, K. T., Krishna, V. V. \& Qaim, M. Production diversity and dietary diversity in smallholder farm households. Proc. Natl Acad. Sci. USA 2015 , 201510982 (2015).

20. Allen, T., Prosperi, P., Cogill, B. \& Flichman, G. Agricultural biodiversity, social-ecological systems and sustainable diets. Proc. Nutr. Soc. 73, 498-508 (2014).

21. Massawe, F., Mayes, S. \& Cheng, A. Crop diversity: an unexploited treasure trove for food security. Trends Plant Sci. 21, 365-368 (2016).

22. Dwivedi, S. L. et al. Diversifying food systems in the pursuit of sustainable food production and healthy diets. Trends Plant Sci. 22, 842-856 (2017).

23. Frison, E. A. et al. Agricultural biodiversity is essential for a sustainable improvement in food and nutrition security. Sustainability 3, 238-253 (2011).

24. Klein, A.-M. et al. Importance of pollinators in changing landscapes for world crops. Proc. R. Soc. B 274, 303-313 (2007).

25. Orgiazzi, A. et al. Global Soil Biodiversity Atlas (European Commission, Publications Office of the European Union, 2016); https://doi.org/ $10.2788 / 799182$

26. Kremen, C., Iles, A. \& Bacon, C. Diversified farming systems: an agroecological, systems-based alternative to modern industrial agriculture. Ecol. Soc. 17, 44 (2012).

27. Khoury, C. K. et al. Comprehensiveness of conservation of useful wild plants: an operational indicator for biodiversity and sustainable development targets. Ecol. Indic. 98, 420-429 (2019).

28. Castañeda-Álvarez, N. P. et al. Global conservation priorities for crop wild relatives. Nat. Plants 2, 16022 (2016).

29. A Global Database for the Distributions of Crop Wild Relatives v.1.12 (Centro Internacional de Agricultura Tropical, 2018); https://doi.org/10.15468/jyrthk

30. Shannon, C. E. \& Weaver, W. The Mathematical Theory of Communication (Univ. of Illinois Press, 1949).

31. Milla, R. Crop Origins and Phylo Food: a database and a phylogenetic tree to stimulate comparative analyses on the origins of food crops. Glob. Ecol. Biogeogr. 29, 606-614 (2020).

32. Hoelzel, A. R., Bruford, M. W. \& Fleischer, R. C. Conservation of adaptive potential and functional diversity. Conserv. Genet. 20, 1-5 (2019).

33. Tamburini, G. et al. Agricultural diversification promotes multiple ecosystem services without compromising yield. Sci. Adv. 6, eaba1715 (2020).

34. Garibaldi, L. A. et al. Working landscapes need at least $20 \%$ native habitat. Conserv. Lett. 14, e12773 (2020).

35. Shackelford, G. et al. Comparison of pollinators and natural enemies: a meta-analysis of landscape and local effects on abundance and richness in crops. Biol. Rev. 88, 1002-1021 (2013).

36. Tuck, S. L. et al. Land-use intensity and the effects of organic farming on biodiversity: a hierarchical meta-analysis. J. Appl. Ecol. 51, 746-755 (2014).

37. Rader, R. et al. Organic farming and heterogeneous landscapes positively affect different measures of plant diversity. J. Appl. Ecol. 51, 1544-1553 (2014)

38. Palm, C., Blanco-Canqui, H., DeClerck, F., Gatere, L. \& Grace, P. Conservation agriculture and ecosystem services: an overview. Agric. Ecosyst. Environ. 187, 87-105 (2014).

39. Altieri, M. A. \& Nicholls, C. I. Agroecology and the emergence of a post COVID-19 agriculture. Agric. Human Values 37, 525-526 (2020).

40. Gemmill-Herren, B. Closing the circle: an agroecological response to COVID-19. Agric. Human Values 37, 613-614 (2020).

41. Tester, M. \& Langridge, P. Breeding technologies to increase crop production in a changing world. Science 327, 818-822 (2010).

42. Swaminathan, M. S. in In Search of Biohappiness: Biodiversity and Food, Health and Livelihood Security (eds Sardar, D. \& Yun, A.) Ch. 9 (World Scientific, 2015).

43. Brown, C., Alexander, P., Arneth, A., Holman, I. \& Rounsevell, M. Achievement of Paris climate goals unlikely due to time lags in the land system. Nat. Clim. Change 9, 203-208 (2019).

44. Love, B. \& Spaner, D. Agrobiodiversity: its value, measurement, and conservation in the context of sustainable agriculture. J. Sustain. Agric. 31, 53-82 (2007).

45. Zimmerer, K. S. et al. The biodiversity of food and agriculture (agrobiodiversity) in the Anthropocene: research advances and conceptual framework. Anthropocene 25, 100192 (2019).

46. Béné, C. et al. Global map and indicators of food system sustainability. Sci. Data 6, 279 (2019).

47. Béné, C. et al. Global drivers of food system (un)sustainability: a multi-country correlation analysis. PLoS ONE 15, e0231071 (2020).

48. Hickey, G. M., Pouliot, M., Smith-Hall, C., Wunder, S. \& Nielsen, M. R. Quantifying the economic contribution of wild food harvests to rural livelihoods: a global-comparative analysis. Food Policy 62, 122-132 (2016).

49. Mainstreaming Agrobiodiversity in Sustainable Food Systems: Scientific Foundations for an Agrobiodiversity Index (Bioversity International, 2017). 
50. The Agrobiodiversity Index Methodology Report Version 1.0 (Bioversity International, 2018).

51. Guidelines for the Preparation of the Country Reports for the State of the World's Biodiversity for Food and Agriculture (SOWBFA) (FAO, 2013); https://doi.org/10.5812/jjm.34804

52. Juventia, S. D. et al. Text mining national commitments towards agrobiodiversity conservation and use. Sustainability 12, 715 (2020)

53. Singh, R. K., Murty, H. R., Gupta, S. K. \& Dikshit, A. K. An overview of sustainability assessment methodologies. Ecol. Indic. 9, 189-212 (2009).

54. Gan, X. et al. When to use what: methods for weighting and aggregating sustainability indicators. Ecol. Indic. 81, 491-502 (2017).

55. Gómez-Limón, J. A. \& Sanchez-Fernandez, G. Empirical evaluation of agricultural sustainability using composite indicators. Ecol. Econ. 69, 1062-1075 (2010).

56. Nardo, M., Saisana, M., Saltelli, A. \& Tarantola, S. Tools for Composite Indicators Building (Joint Research Centre of the European Commission, 2005)

57. Wilson, M. C. \& Wu, J. The problems of weak sustainability and associated indicators. Int. J. Sustain. Dev. World Ecol. 24, 44-51 (2017).

58. Blaser, W. J. et al. Climate-smart sustainable agriculture in low-to-intermediate shade agroforests. Nat. Sustain. 1, 234-239 (2018).

59. Standard Country or Area Codes for Statistical Use (M49) (United Nations Statistics Division, 2012); https://unstats.un.org/unsd/methodology/m49/

60. De Mendiburu, F. Una Herramienta de Analisis Estadistico para la Investigacion Agricola (Universidad Nacional de Ingenieria (UNI-PERU), 2009).

61. Dinno, A. dunn.test: Dunn's test of multiple comparisons using rank sums. R package v.1.3.4 (CRAN, 2017).

62. Warner, R. M. Applied Statistics: From Bivariate Through Multivariate Techniques (SAGE, 2008).

63. $\mathrm{R}$ Core Team $R$ : A language and environment for statistical computing (R Foundation for Statistical Computing, 2018); https://www.r-project.org/

64. Jones, S. K. et al. Agrobiodiversity Index Scores for 80+ Countries (Harvard Dataverse, 2020); https://doi.org/10.7910/DVN/SKZSQD

65. Kennedy, G. et al. in Mainstreaming Agrobiodiversity in Sustainable Food Systems: Scientific Foundations for an Agrobiodiversity Index (ed Bailey, A.) 23-52 (Bioversity International, 2017).

66. Minimum Dietary Diversity for Women: A Guide for Measurement (FAO, FHI, 2016)

67. Ojiewo, C., Tenkouano, C., Hughes, J. \& Keatinge, J. D. H. in Diversifying Food and Diets: Using Agricultural Biodiversity to Improve Nutrition and Health (eds Fanzo, J. et al.) 291-302 (Routledge, 2013).

68. Snyder, L. D., Gómez, M. I. \& Power, A. G. Crop varietal mixtures as a strategy to support insect pest control, yield, economic, and nutritional services. Front. Sustain. Food Syst. 4, 60 (2020).

69. Maureaud, A. et al. Biodiversity-ecosystem functioning relationships in fish communities: biomass is related to evenness and the environment, not to species richness. Proc. R. Soc. B 286, 20191189 (2019).

70. Wang, L. et al. Diversifying livestock promotes multidiversity and multifunctionality in managed grasslands. Proc. Natl Acad. Sci. USA 116 , 6187-6192 (2019).

71. Khumairoh, U., Lantinga, E. A., Schulte, R. P. O., Suprayogo, D. \& Groot, J. C. J. Complex rice systems to improve rice yield and yield stability in the face of variable weather conditions. Sci. Rep. 8, 14746 (2018).

72. Lavorel, S. Plant functional effects on ecosystem services. J. Ecol. 101, 4-8 (2013).

73. Wood, S. A. et al. Functional traits in agriculture: agrobiodiversity and ecosystem services. Trends Ecol. Evol. 30, 531-539 (2015).
74. Martin, A. R. \& Isaac, M. E. Functional traits in agroecology: advancing description and prediction in agroecosystems. J. Appl. Ecol. 55, 5-11 (2018).

75. Stark, J. C. \& Thornton, M. in Potato Production Systems (eds Stark, J. et al.) 87-100 (Springer International, 2020).

76. Taylor, M., Jaenicke, H., Hunter, D., McGregor, A. \& Lyon, G. Diversity for sustaining livelihoods: examples, constraints and lessons learnt. Acta Hortic. 1101, 105-112 (2015).

77. Mulumba, J. W. et al. A risk-minimizing argument for traditional crop varietal diversity use to reduce pest and disease damage in agricultural ecosystems of Uganda. Agric. Ecosyst. Environ. 157, 70-86 (2012).

78. Bartomeus, I. et al. Contribution of insect pollinators to crop yield and quality varies with agricultural intensification. PeerJ 2014, e328 (2014).

79. Fahrig, L. et al. Farmlands with smaller crop fields have higher within-field biodiversity. Agric. Ecosyst. Environ. 200, 219-234 (2015).

80. Maxted, N., Dulloo, M. E. \& Ford Lloyd, B. Enhancing Crop Genepool Use: Capturing Wild Relative and Landrace Diversity for Crop Improvement (CABI, 2016).

81. Li, Y. et al. Investigating drought tolerance in chickpea using genome-wide association mapping and genomic selection based on whole-genome resequencing data. Front. Plant Sci. 9, 190 (2018).

82. Hunter, D. et al. The potential of neglected and underutilized species for improving diets and nutrition. Planta 250, 709-729 (2019).

\section{Acknowledgements}

M. Ramirez, C. Hoogendoorn and R. De Vivo provided review comments that helped improve the manuscript. Members of the ABDI Expert Review Committee and Advisory Panel, colleagues in Bioversity International, CIAT, FAO, ICAR, MINAM, INIA, and the CGIAR Agriculture for Nutrition and Health and Water, Land and Ecosystem Programmes provided scientific input and strategic advice that improved the design of the ABDI. L. Valette helped develop the R scripts used for data compilation. The ABDI was developed with financial support from the European Commission (DEVCO1 FOOD/2016/378-156 and DEVCO 2 FOOD/2017/391-245), the Italian government and the CGIAR Water, Land and Ecosystems research programme.

\section{Author contributions}

R.R. conceived the ABDI. S.K.J., R.R., N.E.-C., S.D.J. and M.-A.L. sourced the data used in the paper. S.K.J. compiled the data and conducted the analysis. S.K.J., M.E.D., N.E.-C. S.D.J. and R.R. interpreted the results. S.K.J. led the writing with contributions from all authors.

\section{Competing interests}

The authors declare no competing interests.

\section{Additional information}

Supplementary information The online version contains supplementary material available at https://doi.org/10.1038/s43016-021-00344-3.

Correspondence and requests for materials should be addressed to Sarah K. Jones.

Peer review information Nature Food thanks Delphine Renard and the other, anonymous, reviewer(s) for their contribution to the peer review of this work.

Reprints and permissions information is available at www.nature.com/reprints.

Publisher's note Springer Nature remains neutral with regard to jurisdictional claims in published maps and institutional affiliations.

(c) The Author(s), under exclusive licence to Springer Nature Limited 2021 